\title{
MicroRNAs as regulators in plant metal toxicity response
}

\author{
Ana B. Mendoza-Soto ${ }^{1}$, Federico Sánchez ${ }^{2}$ and Georgina Hernández ${ }^{1}$ * \\ ${ }^{1}$ Centro de Ciencias Genómicas, Universidad Nacional Autónoma de México, Cuernavaca, Morelos, México \\ ${ }^{2}$ Instituto de Biotecnología, Universidad Nacional Autónoma de México, Cuernavaca, Morelos, México
}

\section{Edited by:}

Anireddy S. N. Reddy, Colorado State University, USA

\section{Reviewed by:}

Yao-Guang Liu, South China Agricultural University, China Jingfa Xiao, Beijing Institute of Genomics, Chinese Academy of Sciences, China

\section{${ }^{*}$ Correspondence:}

Georgina Hernández, Centro de Ciencias Genómicas, Universidad Nacional Autónoma de México, Av Universidad 1001, Cuernavaca, Morelos 62209, México.

e-mail: gina@ccg.unam.mx
Metal toxicity is a major stress affecting crop production. This includes metals that are essential for plants (copper, iron, zinc, manganese), and non-essential metals (cadmium, aluminum, cobalt, mercury). A primary common effect of high concentrations of metal such as aluminum, copper, cadmium, or mercury is root growth inhibition. Metal toxicity triggers the accumulation of reactive oxygen species leading to damage of lipids, proteins, and DNA. The plants response to metal toxicity involves several biological processes that require fine and precise regulation at transcriptional and post-transcriptional levels. MicroRNAs (miRNAs) are 21 nucleotide non-coding RNAs that regulate gene expression at the post-transcriptional level. A miRNA, incorporated into a RNA-induced silencing complex, promotes cleavage of its target mRNA that is recognized by an almost perfect base complementarity. In plants, miRNA regulation is involved in development and also in biotic and abiotic stress responses. We review novel advances in identifying miRNAs related to metal toxicity responses and their potential role according to their targets. Most of the targets for plant metal-responsive miRNAs are transcription factors. Information about metal-responsive miRNAs in different plants points to important regulatory roles of miR319, miR390, miR393, and miR398. The target of miR319 is the TCP transcription factor, implicated in growth control. miR390 exerts its action through the biogenesis of trans-acting small interference RNAs that, in turn, regulate auxin responsive factors. miR393 targets the auxin receptors TIR1/AFBs and a bHLH transcription factor. Increasing evidence points to the crucial role of miR398 and its targets $\mathrm{Cu} / \mathrm{Zn}$ superoxide dismutases in the control of the oxidative stress generated after high copper or iron exposure.

\section{Keywords: microRNAs, metal toxicity, abiotic stress}

\section{PLANT RESPONSE TO METAL TOXICITY}

Plants are constantly exposed to numerous abiotic and biotic stresses. One important abiotic stress is metal toxicity. Heavy metals such as copper $(\mathrm{Cu})$, iron $(\mathrm{Fe})$, and zinc $(\mathrm{Zn})$ are essential for physiological and biochemical processes, and metals such as cadmium (Cd), cobalt (Co), mercury $(\mathrm{Hg})$, and aluminum $(\mathrm{Al})$ are non-essential. Nevertheless, high concentrations of any metal type is toxic for the plant.

One of the primary symptoms of toxicity of metals such as $\mathrm{Al}, \mathrm{Cu}, \mathrm{Cd}$, and $\mathrm{Hg}$ is root growth inhibition, with the root apex being the most sensitive part of the root (Schützendübel et al., 2001; Kochian et al., 2005; Rellán-Álvarez et al., 2006; Lequeux et al., 2010).

Plant responses to cope with metal toxicity include the synthesis of different proteins involved in detoxification, such as phytochelatins and metallothioneins (Cobbett and Goldsbrough, 2002). Root exudation of organic acids - citric, oxalic, malic - and amino acids - histidine - to the rhizosphere is an important physiological response since these compounds can form complexes with the heavy metals leading to detoxification (Hall, 2002).

The expression of several metal transporters is essential for tolerance to metal toxicity. The ABC-transporters (ATP-binding cassette) family mediates the transport of Al and Cd (Kim et al., 2007; Huang etal., 2012). The NRAMP (natural resistanceassociated macrophage protein) family regulates responses to $\mathrm{Cd}$, manganese (Mn), and $\mathrm{Zn}$ transport (DalCorso et al., 2010). The CDF (cation diffusion facilitator) family, involved in cytoplasmic efflux and vacuolar sequestration of divalent metal cations, plays a role in $\mathrm{Zn}, \mathrm{Cd}, \mathrm{Co}$, nickel $(\mathrm{Ni})$, or $\mathrm{Mn}$ metal toxicities (Krämer et al., 2007). Transporters from the P-type ATPases ion pumps systems have been linked to the transport of heavy metals such as $\mathrm{Cu}$, $\mathrm{Zn}$, Cd, and lead (Pb; Axelsen and Palmgren, 2001; Andres-Colas et al., 2006; Lee et al., 2007).

Metal toxicity stress triggers the accumulation of ROS (reactive oxygen species), unbalancing the activity of antioxidative enzymes that are up-regulated by this stress (Romero-Puertas et al., 2007). Oxidative stress leads to damage of lipids, proteins, and DNA (Schützendübel and Polle, 2002).

Plant response to abiotic stress such as metal toxicity involves a precise regulation of gene expression at the transcriptional and post-transcriptional levels. Regulation can be achieved by transcription factors (TF) from different families such as myeloblastosis protein (MYB), basic leucine Zipper (bZIP), ethylene-responsive factor (ERF), and WRKY (Jacoby et al., 2002; Krämer etal., 2007; Wei et al., 2008; Farinati et al., 2010). Cisacting elements have been identified in the promoter regions of metal-responsive genes such as parA, an auxin-regulated gene, involved in Cd-response in Nicotiana tabacum (Kusaba et al., 1996). The Cu-response element (CuRE) with a consensus GTAC was identified in the promoter of the coprogen oxidase and the 
cytochrome $c_{6}$ genes from the green algae Chlamydomonas reinhardtii (Quinn et al., 2000). Two promoter regions of the PvSR2 gene from Phaseolus vulgaris contain heavy metal-responsive elements (HMREs; Qi et al., 2007).

Small and/or large non-protein coding RNAs (npcRNAs) may be involved in the regulation/signaling of metal toxicity response (Jones-Rhoades et al., 2006; Hobert, 2008; Ben Amor et al., 2009). One of the most studied classes of npcRNAs is the micro RNAs (miRNAs). miRNAs are 21 nucleotide npcRNAs that regulate gene expression at the post-transcriptional level in plants. A precursor miRNA (pre-miRNA) with imperfect hairpin structure is processed into a mature miRNA and this is incorporated into a RNA-induced silencing complex (RISC) that promotes degradation/cleavage of the corresponding target mRNA(s), recognized by an almost perfect base complementarity with the miRNA (Jones-Rhoades et al., 2006). Though most of the miRNAs identified in Arabidopsis thaliana are related to plant development, there is evidence of the role of miRNAs in the plant response to different abiotic stresses including metal toxicity (Jones-Rhoades and Bartel, 2004; Fujii et al., 2005; Sunkar et al., 2006; Phillips et al., 2007; Reyes and Chua, 2007; Li et al., 2008).

\section{miRNAs AND THEIR TARGETS IN METAL TOXICITY}

Analyses of small RNAs expression profiles performed in plants exposed to metal toxicities has shown the differential expression of miRNA and their targets, thus indicating their possible role in regulation/signaling pathways. To determine the role of a specific miRNA it is important to analyze the function of its target(s) and their possible interactions with signaling pathways related to metal toxicity responses. Most of the targets predicted for metal-responsive conserved miRNAs are TF mainly involved in plant development (Table 1). Up-regulation of a certain miRNA resulting in its target degradation might indicate the target role as a negative regulator of metal toxicity response. Recent high-throughput genomic technologies as well as other geneticgenomic approaches have increased our current knowledge of miRNAs and their target in signaling pathways for metal toxicities response in several plant species (Sunkar and Zhu, 2004; Phillips et al., 2007; Huang et al., 2009; Ding et al., 2011; Chen et al., 2012; Zhou et al., 2012).

In regard to miRNAs that respond to Cd-toxicity the conserved miRNAs: miR160, miR164, and miR167 and the novel of OsamiR602 and Osa-miR604 were identified in a library of small RNAs from rice seedlings exposed to Cd (Huang et al., 2009). Osa-miR602 is up-regulated in rice roots exposed for $12 \mathrm{~h}$ to high Cd; its predicted target is a xyloglucan endotransglocosylase/hydrolase. Osa-miR604, which was up-regulated in leaves treated with toxic levels of $\mathrm{Cd}$ for $6 \mathrm{~h}$, down-regulated a lipid transfer protein (LPT; Huang et al., 2009). This type of protein is responsive to environmental stresses and to abscisic acid, salicylic acid, ethylene, and methyl jasmonate that has been proposed to participate in cutin and wax assembly and in defense of plant against pathogens (Arondel et al., 2000; Kim et al., 2008). Rice microarray data showed that miR528 is up-regulated, while miR162, miR166, mir171, miR390, miR168, and miR156 families were down-regulated under Cd stress (Ding et al., 2011). The search of possible metal-responsive cis-acting elements revealed that a MRE-like sequence ( $5^{\prime}$-TGCGCNC- $\left.3^{\prime}\right)$ is present in promoter regions of most of the Cd-responsive miRNA genes (Ding et al., 2011). Other cis-acting elements related to different abiotic stresses such as ARE (anaerobic-responsive element); ABRE (ABAresponsive element); GARE (gibberellins-responsive element); ERE (ethylene-responsive element); HSE (heat stress-responsive element); and LTR (low temperature-responsive element) were also identified in these miRNA genes promoters, thus implying that these miRNAs could be responsive to other stress signals besides metal toxicity (Ding et al., 2011). In roots of Brassica napus miR393, miR171, miR156, and miR396 are down-regulated after Cd exposure (8 h; Xie et al., 2007).

Table 1 | Metal toxicity-responsive miRNAs.

\begin{tabular}{llll}
\hline Related metal toxicity & miRNA & Targets & Reference \\
\hline $\mathrm{Cd}, \mathrm{Hg}, \mathrm{Al}, \mathrm{Mn}$ & miR319 & TCP transcription factors & Zhou et al. (2008), Valdés-López et al. (2010), Chen et al. (2012) \\
$\mathrm{Cd}, \mathrm{Hg}, \mathrm{Al}$ & miR171 & SCL transcription factors & Xie et al. (2007), Zhou et al. (2008, 2012) \\
$\mathrm{Cd}, \mathrm{Hg}, \mathrm{Al}$ & miR390 & TAS3 & Ding et al. (2011), Chen et al. (2012), Zhou et al. (2012) \\
$\mathrm{Cd}, \mathrm{Hg}, \mathrm{Al}$ & miR393 & TIR1/AFBs (F-box auxin receptors) & Xie et al. (2007), Zhou et al. (2008) \\
& & and bHLH transcription factors & \\
$\mathrm{Cd}, \mathrm{Hg}, \mathrm{Al}$ & miR396 & GRF transcription factors & Xie et al. (2007), Chen et al. (2012), Zhou et al. (2012) \\
$\mathrm{Cd}, \mathrm{Hg}, \mathrm{Mn}$ & miR167 & Auxin responsive factors (ARFs) & Huang et al. (2009), Valdés-López et al. (2010), Zhou et al. (2012) \\
$\mathrm{Cd}, \mathrm{Hg}$ & miR164 & NAC, CUP trancription factors & Huang et al. (2009), Zhou et al. (2012) \\
$\mathrm{Cd}, \mathrm{Al}$ & miR160 & Auxin responsive factors (ARFs) & Huang et al. (2009), Chen et al. (2012) \\
$\mathrm{Cd}$ & miR156 & SBP transcription factors & Xie et al. (2007), Ding et al. (2011) \\
$\mathrm{Cu}, \mathrm{Fe}, \mathrm{Mn}$ & miR398 & CSD, COX5b.1, CCS & Sunkar et al. (2006), Zhou et al. (2008), Valdés-López et al. (2010) \\
$\mathrm{Hg}, \mathrm{Mn}$ & miR172 & AP2 transcription factors & Valdés-López et al. (2010), Zhou et al. (2012) \\
$\mathrm{Mn}$ & miR397 & Laccases & Valdés-López et al. (2010)
\end{tabular}


In leaves of the model legume Medicago truncatula miR393, miR171, miR319, and miR529 are up-regulated, while miR166 and miR398 are down-regulated after $\mathrm{Cd}, \mathrm{Hg}$, and $\mathrm{Al}$ exposure (24 h; Zhou et al., 2008). A high-throughput small RNAsequencing approach revealed that miR159, miR160, miR319, miR396, and miR390 were down-regulated in response to $\mathrm{Al}$ (Chen etal., 2012). More recently a study using a similar approach identified Hg-toxicity responsive miRNAs such as the miR167, miR172, miR169, miR164, miR395 families that are up-regulated, whereas the miR396, miR390, and miR171 are down-regulated in this legume. In addition, new $M$. truncatula Hg-responsive miRNAs were identified such as miR2681 targets the transcripts coding TIR-NBS-LRR disease resistance proteins (Zhou et al., 2012).

Our group has reported the miRNA expression profile in common bean (P. vulgaris), the most important legume for human consumption. Using a miRNA-macroarray hybridization approach we identified miRNAs that respond to nutrient deficiencies and to Mn-toxicity in different plant organs. In common bean plants exposed to high Mn miR397 is down-regulated in leaves, miR319 and miR398 are up-regulated in roots and nodules, miR172 is up-regulated in nodules and miR167 is up-regulated in roots (Valdés-López et al., 2010). Recently, the identification and characterization of miRNAs in $P$. vulgaris by high-throughput sequencing has been completed (Peláez et al., 2012).

Current information about metal-responsive miRNAs in different plants indicates the common relevant role of miR319, miR390, miR393, and miR398.

\section{ROLES OF miR319, miR390, miR393, AND miR398 miR319}

Plant growth and senescence are processes affected by metal toxicity (Maksymiec, 2007). Common responses of shoots to $\mathrm{Al}$ - and $\mathrm{Cu}$-toxicity include cellular and ultrastructural changes in leaves, decreased photosynthetic activity leading to chlorosis and necrosis of leaves, total decrease in leaf number and size, and decreased shoot biomass (Thornton et al., 1986; Lanaras et al., 1993; Maksymiec, 1997; Panou-Filotheou et al., 2001). In addition, $\mathrm{Cu}$-toxicity leads to rapid senescence in leaves (Luna et al., 1994). Interestingly, miR319 and its target TCP (Teosinte Branched/ Cycloidea/PCF) TF (Table 1), implicated in growth control, have shown differential expression in most of the studies of miRNAs responding to metal toxicity. Members of the TCP family bind to promoter elements which are essential for the expression of the proliferating cell nuclear antigen (PCNA) gene (Kosugi and Ohashi, 1997). Other TCPs are involved in the morphogenesis of shoot lateral organs (Li et al., 2005). Lately, it has been demonstrated that miR319 plays a role on leaf senescence through the regulation of TCPs that positively control leaf senescence via JA biosynthesis and important senescence positive regulators like WRKY53 (Schommer et al., 2008).

Figure 1 depicts the mode of action of miR319 and TCP. In leaves, high $\mathrm{Cd}, \mathrm{Hg}$, and $\mathrm{Al}$ induce miR319 leading to the degradation of TCP thus affecting growth and senescence. In the roots, this miRNA is repressed in response to $\mathrm{Al}$ while it is induced in Mn-toxicity (Valdés-López et al., 2010; Chen et al., 2012). The opposite regulation of miR319 could be due to the

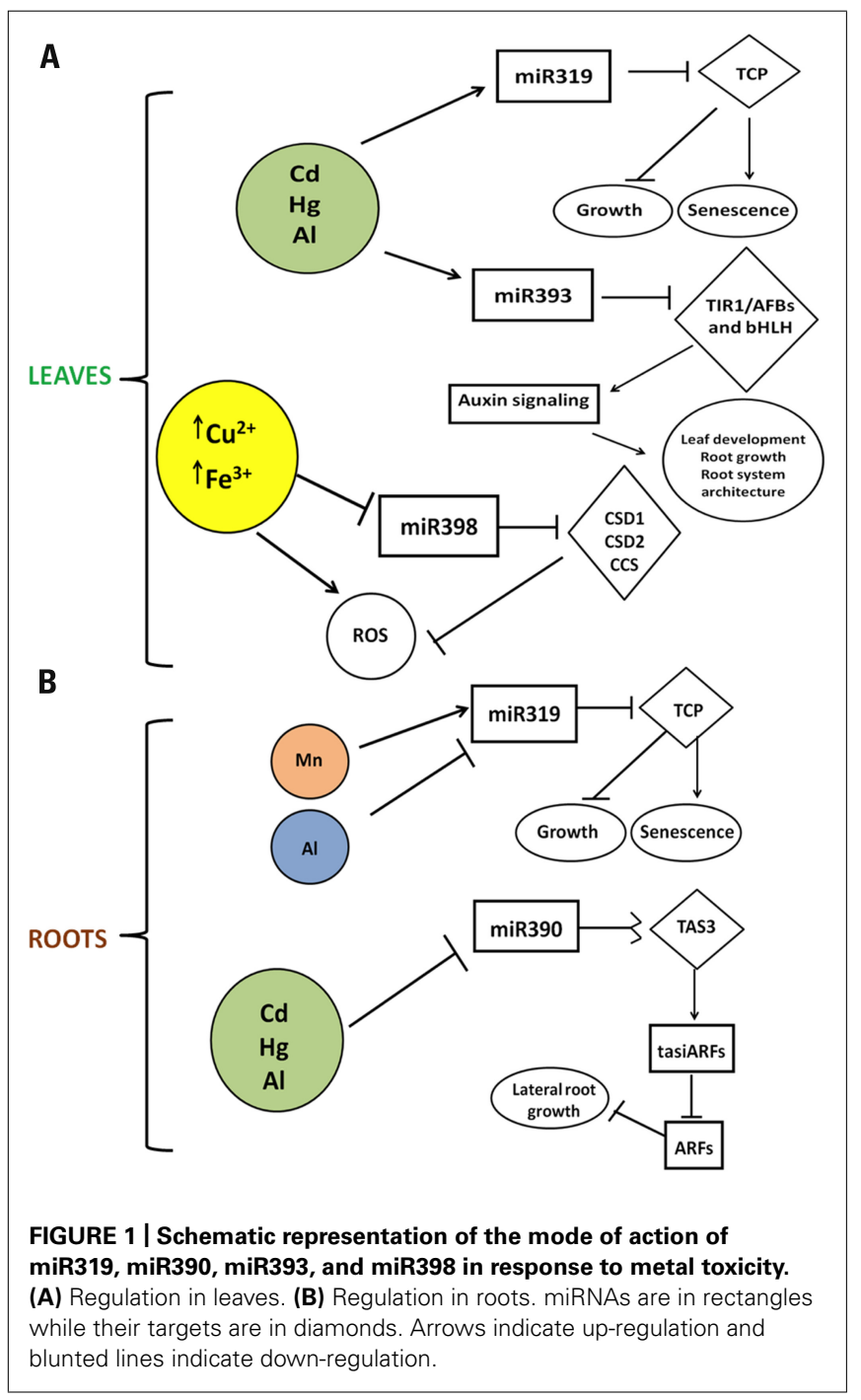

different plant species and/or the different time of exposure and metal concentration used. When both metals are abundant in the ground $\mathrm{Al}$ may exert an antagonistic effect on the uptake of Mn thus ameliorating Mn-toxicity (Blair and Taylor, 1997; Yang etal., 2009). There are no reports about the regulation of miR319 when plant roots are exposed to the combination of $\mathrm{Al}$ and $\mathrm{Mn}$; we find difficult to speculate about this issue since specific effects in the plant would depend on several variables (concentration, time of exposure, environmental conditions).

\section{miR390}

miR390 and its target TAS3 (Table 1) are related to metal toxicity response in different plants. The miR390-induced cleavage of TAS3 transcript initiates ta-siRNAs (trans-acting small interference RNAs) biogenesis, leading to the degradation of ARFs (auxin response factors) that play critical roles in lateral root development (Marin et al., 2010). miR390 is repressed in roots of plants under $\mathrm{Cd}, \mathrm{Al}$, and $\mathrm{Hg}$ toxicities, which would lead the accumulation of intact TAS3 transcript and the decrease of tasiARFs resulting in 
the inhibition of lateral root growth (Chen et al., 2011; Zhou et al., 2012; Figure 1).

Arabidopsis plants exposed to high $\mathrm{Cu}$ show decreased primary root growth and increased short lateral root density. Also, changes in auxin and cytokinin accumulation and in mitotic activity within the primary and secondary root tips were observed in $\mathrm{Cu}$-exposed plants (Lequeux et al., 2010). We may speculate that miR390 and its targets could also respond to $\mathrm{Cu}$-toxicity, but no information about miR390 regulation in this stress is available.

\section{miR393}

miR393 is regulated by $\mathrm{Cd}, \mathrm{Hg}$, and $\mathrm{Al}$ toxicities (Xie et al., 2007; Zhou et al., 2008). These metals induce miR393 in leaves, which would lead to the repression of its targets the F-box auxin receptors TIR1/AFBs and bHLH transcription factors (Table 1; Jones-Rhoades and Bartel, 2004; Navarro et al., 2006). TIR1 positively regulates auxin signaling, its level would be low when the miR393 increases leading to an inhibition of auxin signaling. Studies have shown the importance of miR393 regulation of leaf development, root system architecture, and root growth (Vidal etal., 2010; Si-Ammour etal., 2011; Chen et al., 2011; Figure 1). This miRNA also responds to bacterial infection with Pseudomonas syringae and to salinity (Navarro et al., 2006; Gao et al., 2011).

The root is the main organ affected by high concentration of metals such as $\mathrm{Cu}, \mathrm{Cd}, \mathrm{Cu}, \mathrm{Hg}$, and $\mathrm{Al}$ in the soil, and the common phenotypic response is changes in architecture (Karataglis et al., 1988; Kahle, 1993; Kochian et al., 2005). In such responses miR393 and miR390 may play relevant regulatory roles.

\section{miR398}

miR398 was the first miRNA identified to be regulated by oxidative stress. Its targets are the $\mathrm{Cu} / \mathrm{Zn}$ superoxide dismutases (CSD) enzymes: cytosolic CSD1 and plastidic CSD2 such as the COX5b.1, the $5 \mathrm{~b}$ subnunit of mitochondrial cytochrome oxidase (Table 1). CSDs are enzymes that scavenge superoxide radicals to release molecular oxygen and hydrogen peroxide, which are less ROS (Kliebenstein etal., 1998). The CSD2 mRNA sequence that is complementary to miR398 is within the coding sequence while CSD1 and COX5b.1 transcripts contain miR398 complementary sequence in the 5'UTR (Bonnet et al., 2004; Jones-Rhoades and Bartel, 2004; Sunkar and Zhu, 2004).

The miR398 promoter contains the GTAC sequence that has an important feature in Cu responsiveness (Yamasaki et al., 2009). This motif is recognized by the SPL7 TF that binds to the promoter and regulates the expression of miR398. In addition, this TF regulates the expression of other Cu-related miRNAs: miR397, mir408, and miR857 (Ding and Zhu, 2009). The GTAC promoter sequence is also present in other important $\mathrm{Cu}$-responsive genes such as CPX1 (coproporphyrinogen oxidase) and Cyc6 (cytochrome 1 c6) that improve the ability to assimilate $\mathrm{Cu}$ under $\mathrm{Cu}$ deficiency (Hill and Merchant, 1995; Quinn et al., 2000).

Oxidative stress suppresses miR398 expression that is essential for the accumulation of CSD1 and CSD2 transcripts (Figure 1). miR398 is down-regulated upon exposure to heavy metals such as $\mathrm{Cu}^{2+}$ and $\mathrm{Fe}^{3+}$ (Sunkar et al., 2006) that are involved in Fentontype reactions and have potential to generate hydroxyl radicals
(Dietz etal., 1999; Estevez et al., 2001). In addition, miR398 is down-regulated in response to high light and MV (methyl viologen) when the levels of CSD1 and CSD2 transcripts usually are increased (Sunkar et al., 2006; Yamasaki et al., 2007).

The co-supressed transgenic lines, over-expressing miR398 precursors, display an increased tolerance to $\mathrm{Cu}^{2+}$ and to MV stresses in terms of seedling development and lipid peroxidation rates (Sunkar et al., 2006). In contrast, some reports show that over-expression of miR398b and miR398c is possible and the over-expressing lines show reduced CSD1 and CSD2, but not COX5b.1, mRNA, and protein levels (Yamasaki et al., 2007; Dugas and Bartel, 2008).

Sucrose is an important signal for miR398 expression; it positively regulates this miRNA accumulation. In agreement CSD1 and CSD2 protein levels, but not COX5b.1, levels decreased as sucrose is increased. The increase in the miR398 level by sucrose is maintained both in the presence and in the absence of $\mathrm{Cu}$, thus miR398 regulation by sucrose and by $\mathrm{Cu}$ are independent (Dugas and Bartel, 2008).

The $\mathrm{Cu}$ chaperone for superoxide dismutase (CCS1) was recently identified as a miR398 target; its mRNA cleavage is mediated by miR398 when $\mathrm{Cu}$ is scarce (Beauclair et al., 2010). CCS1 delivers $\mathrm{Cu}$ to CSDs (Abdel-Ghany et al., 2005). Beauclair et al. (2010) proposed that the regulation of CCS1 by miR398 could be responsible for the unchanged protein levels of CSD1 and CSD2 in studies of plants expressing miR398-resistant forms of CSD1 or CSD2 (Dugas and Bartel, 2008).

Furthermore, miR398 has a role in biotic stress. This miRNA decreases in Arabidopsis leaves infiltrated with avirulent strains of Pseudomonas syringae pv tomato, CSD1 was negatively correlated with miR398 levels. Avirulent strains induce a biphasic accumulation of ROS (oxidative burst) leading to the accumulation of ROS at the beginning of the hypersensitive response and at a second phase accompanied by local cell death (Lamb and Dixon, 1997; Wojtaszek, 1997; Torres et al., 2006). Plants exposed to virulent strains do not show drastic changes in the levels of miR398, which could be due to the absence of the oxidative burst or to the presence of just the initial accumulation of ROS (Jagadeeswaran et al., 2009) and the negative regulation of the signaling cascade induced by the T3SS proteins that target key cellular functions (Jones and Dangl, 2006).

Apparently, the common signal of the abiotic stresses such as $\mathrm{Cu}^{2+}, \mathrm{Fe}^{3+}$, high light, $\mathrm{MV}$, ozone, salinity, and the biotic stress (avirulent strains) is the accumulation of ROS. The generation of ROS is one of the common responses to metal toxicities as well as the synthesis of active antioxidative enzymes. Both responses vary among different metal exposures (Sharma and Dietz, 2009), the specific response of miR398 or other ROS-responsive miRNAs may vary according to the metal and to the time of exposure to the stress (Figure 1).

\section{CONCLUDING REMARKS}

The identification and analysis of miRNAs responsive to different metal toxicities has provided information about their possible relations in the networks involved in plant adaptation to these abiotic stresses. These studies are recent so we can predict the discovery of additional novel metal stress-responsive miRNAs. 
Further research is needed to deeply understand the role of miRNAs and their targets, mainly TFs, as main players in signaling pathways of plant responses to environmental changes. This should take into account that plant species varying in growth habits and genotypic backgrounds may have differential responses of miRNAs to metal stresses. More detailed analysis on the kinetics of miRNAs and target regulation over a time-course of metal exposure, including different metal concentration and combinations of metals, will be helpful for obtaining better mechanistic insights into the roles of miRNAs in stress-regulatory networks. To elucidate novel roles of miRNAs in the response to metal toxicities

\section{REFERENCES}

Abdel-Ghany, S. E., Burkhead, J. L., Gogolin, K. A., Andres-Colas, N., Bodecker, J. R., Puig, S., Penarrubia, L., and Pilon, M. (2005). AtCCS is a functional homolog of the yeast copper chaperone Ccs1/Lys7. FEBS Lett. 579, 2307-2312.

Andres-Colas, N., Sancenon, V., Rodriguez-Navarro, S., Mayo, S., Thiele, D. J., Ecker, J. R., Puig, S., and Penarrubia, L. (2006). The Arabidopsis heavy metal P-type ATPase HMA5 interacts with metallochaperones and functions in copper detoxification of roots. Plant J. 45, 225-236.

Arondel, V., Vergnolle, C., Cantrel, C., and Kader, J. C. (2000). Lipid transfer proteins are encoded by a small multigene family in Arabidopsis thaliana. Plant Sci. 157, 1-12.

Axelsen, K. B., and Palmgren, M. G. (2001). Inventory of the superfamily of P-type ion pumps in Arabidopsis. Plant Physiol. 126, 696-706.

Beauclair, L., Yu, A., and Bouché, N. (2010). MicroRNA-directed cleavage and translational repression of the copper chaperone for superoxide dismutase mRNA in Arabidopsis. Plant J. 62, 454-462.

Ben Amor, B., Wirth, S., Merchan, F., Laporte, P., Aubenton-Carafa, Y., Hirsch, J., Maizel, A., Mallory, A., Lucas, A., Deragon, J. M., Vaucheret, H., Thermes, C., and Crespi, M. (2009). Novel long non-proteincoding RNAs involved in Arabidopsis differentiation and stress responses. Genome Res. 19, 57-69.

Blair, L. M., and Taylor, G. J. (1997). The nature of interaction between aluminum and manganese on growth and metal accumulation in Triticum aestivum. Environ. Exp. Bot. 37, 25-37.

Bonnet, E., Wuyts, J., Rouzé, P., and Van de Peer, Y. (2004). Detection of 91 potential conserved plant microRNAs in Arabidopsis thaliana and Oryza sativa identifies important target genes. Proc. Natl. Acad. Sci. U.S.A. 101, 11511-11516.
Chen, L., Wang, T., Zhao, M., Tian, Q., and Zhang, W. H. (2012). Identification of aluminum-responsive microRNAs in Medicago truncatula by genome-wide high-throughput

Chen, Z. H., Bao, M. L., Sun, Y. Z., Yang, Y. J., Xu, X. H., Wuang, J. H., Han, N., Bian, H. W., and Zhu, M. Y. (2011). Regulation of auxin response by miR393-targeted transport inhibitor response protein 1 is involved in normal development in Arabidopsis. Plant Mol. Biol. 77, 619-629.

Cobbett, C. S., and Goldsbrough, P. (2002). Phytochelatins and metallothioneins: roles in heavy metal detoxification and homeostasis. Annu. Rev. Plant Physiol. Plant Mol. Biol. 53, 159-182. (2010). Regulatory networks of cadmium stress in plants. Plant Signal Behav. 5, 663-667.

Dietz, K. J., Baier, M., and Krämer, U. (1999). "Free radicals and reactive oxygen species as mediators of heavy metal toxicity in plants," in Heavy Metal Stress in Plants: From Molecules to Ecosystems, eds M. N. V. Prasad and J. Hagemeyer (Berlin: Springer-Verlag), 73-97.

Ding, Y., Chen, Z., and Zhu, C. (2011). Microarray-based analysis of cadmium-responsive microRNAs in rice (Oryza sativa). J. Exp. Bot. 62, 3563-3573.

Ding, Y. F., and Zhu, C. (2009). The role of microRNAs in cooper and cadmium homeostasis. Biochem. Biophys. Res. Commun. 386, 6-10.

Dugas, D. V., and Bartel, B. (2008). Sucrose induction of Arabidopsis miR398 represses two $\mathrm{Cu} / \mathrm{Zn}$ superoxide dismutases. Plant Mol. Biol. 67, 403-417.

Estevez, M. S., Malanga, G., and Puntarulo, S. (2001). Iron-dependent oxidative stress in Chlorella vulgaris. Plant Sci. 161, 9-17.

Farinati, S., DalCorso, G., Varotto, S., and Furini, A. (2010). The Brassica juncea BjCdR15, an ortholog sequencing. Planta 235, 375-386.

DalCorso, G., Farinati, S., and Furini, A.

it is important to perform phenotypic analysis of plants with modulated expression of a specific miRNA and/or its respective targets. A better understanding of the role of miRNAs during metal stress will contribute to the better design of strategies aimed at improving stress tolerance of crop plants.

\section{ACKNOWLEDGMENTS}

Ana B. Mendoza-Soto is a $\mathrm{PhD}$ student from Doctorado en Ciencias Biomédicas-UNAM and a recipient of a studentship from CONACyT, México (34786). We thank Michael Dunn (CCG-UNAM) for critically reviewing the manuscript.

of Arabidopsis TGA3, is a regulator of cadmium uptake, transport and accumulation in shoots and confers cadmium tolerance in transgenic plants. New Phytol. 185, 964-978.

Fujii, H., Chiou, T. J., Lin, S. I., Aung, K., and Zhu, J. K. (2005). A miRNA involved in phosphatestarvation response in Arabidopsis. Curr. Biol. 15, 2038-2043.

Gao, P., Bai, X., Yang, L., Lv, D., Pan, X., Li, Y., Cai, H., Ji, W., Chen, Q., and Zhu, Y. (2011). osa-MIR393: a salinity- and alkaline stress-related microRNA gene. Mol. Biol. Rep. 38, 237-242.

Hall, J. L. (2002). Cellular mechanisms for heavy metal detoxification and tolerance. J. Exp. Bot. 53, 1-11.

Hill, K. L., and Merchant, S. (1995) Coordinate expression of coproporphyrinogen oxidase and cytochrome c6 in the green alga Chlamydomonas reinhardtii in response to changes in copper availability. EMBO J. 14, 857-865.

Hobert, O. (2008). Gene regulation by transcription factors and microRNAs. Science 319, 1785-1786.

Huang, C. F., Yamaji, N., Chen, Z., and Ma, J. F. (2012). A tonoplastlocalized half-size $\mathrm{ABC}$ transporter is required for internal detoxification of aluminum in rice. Plant J. 69, 857-867.

Huang, S. Q., Peng, J., Qiu, C. X., and Yang, Z. M. (2009). Heavy metalregulated new microRNAs from rice. J. Inorg. Biochem. 103, 282-287.

Jacoby, M., Weisshaar, B., VicenteCarbajosa, J., Tiedemann, J., Kroj, T., and Parcy, F. (2002). bZIP transcription factors in Arabidopsis. Trends Plant Sci. 7, 106-111.

Jagadeeswaran, G., Saini, A., and Sunkar, R. (2009). Biotic and abiotic stress downregulate miR398 expression in Arabidopsis. Planta 229, 1009-1014.

Jones, J. D., and Dangl, J. L. (2006). The plant immune system. Nature 444, 323-329.

Jones-Rhoades, M. W., and Bartel, D. P. (2004). Computational identification of plant microRNAs and their targets, including a stress-induced miRNA. Mol. Cell 14, 787-799.

Jones-Rhoades, M. W., Bartel, D. P., and Bartel, B. (2006). MicroRNAs and their regulatory roles in plants. Annu. Rev. Plant Biol. 57, 19-53.

Kahle, H. (1993). Response of roots to stress of heavy metals. Environ. Exp. Bot. 33, 99-119.

Karataglis, S., Symeonidis, L., and Moustakas, M. (1988). Effect of toxic metals on the multiple forms of esterases of Triticum aestivum cv. Vergina. J. Agron. Crop Sci. 160, 106-112.

Kim, D. Y., Bovet, L., Maeshima, M., Martinoia, E., and Lee, Y. (2007). The ABC transporter AtPDR8 is a cadmium extrusion pump conferring heavy metal resistance. Plant J. 50, 207-218.

Kim, T. H., Park, J. H., Kim, M. C., and Cho, S. H. (2008). Cutin monomer induces expression of the rice OsLTP5 lipid transfer protein gene. J. Plant Physiol. 165, 345-349.

Kliebenstein, D. J., Monde, R. A., and Last, R. L. (1998). Superoxide dismutase in Arabidopsis: an eclectic enzyme family with disparate regulation and protein localization. Plant Physiol. 118, 637-650.

Kochian, L. V., Piñeros, M. A., and Hoekenga, O. A. (2005). The physiology, genetics and molecular biology of plant aluminum resistance and toxicity. Plant Soil 274, 175-195.

Kosugi, S., and Ohashi, Y. (1997). PCF1 and PCF2 specifically bind to cis elements in the rice proliferating cell nuclear antigen gene. Plant Cell 9, 1607-1619.

Krämer, U., Talke, I. N., and Hanikenne, M. (2007). Transition metal transport. FEBS Lett. 581, 2263-2272.

Kusaba, M., Takahashi, Y., and Nagata, T. (1996). A multiplestimuli-responsive as-7-related element of parA gene confers responsiveness to cadmium but not to copper. Plant Physiol. 111, 1161-1167.

Lamb, C., and Dixon, R. A. (1997). The oxidative burst in plant disease 
resistance. Annu. Rev. Plant Phisiol. Plant Mol. Biol. 48, 251-275.

Lanaras, T., Moustakas, M., Symeonidis, L., Diamantoglou, S., and Karataglis, S. (1993). Plant metal content growth responses and some photosynthetic measurements on fieldcultivated wheat growing on one bodies enriched in Cu. Physiol. Plant. 88, 307-314.

Lee, S., Kim, Y.-Y., Lee, Y., and An, G. (2007). Rice $P_{1 B}$-type heavy-metal ATPase, OsHMA9, is a metal efflux protein. Plant Physiol. 145, 831-842.

Lequeux, H., Hermans, C., Lutts, S., and Verbruggen, N. (2010). Response to copper excess in Arabidopsis thaliana: impact on the root system architecture, hormone distribution, lignin accumulation and mineral profile. Plant Physiol. Biochem. 48, 673-682.

Li, C., Potuschak, T., Colón-Carmona, A., Gutiérrez, R. A., and Doerner, P. (2005). Arabidopsis TCP20 links regulation of growth and cell division control pathways. Proc. Natl. Acad. Sci. U.S.A. 102, 12978-12983.

Li, W. X., Oono, Y., Zhu, J., He, X. J., Wu, J. M., Iida, K., Lu, X. Y., Cui, X., Jin, H., and Zhu, J.-K. (2008). The Arabidopsis NFYA5 transcription factor is regulated transcriptionally and posttranscriptionally to promote drought resistance. Plant Cell 20, 2238-2251.

Luna, C. M., González, C. A., and Trippi, V. S. (1994). Oxidative damage caused by an excess of copper in oat leaves. Plant Cell Physiol. 35, 11-15.

Maksymiec, W. (1997). Effect of copper on cellular processes in higher plants. Photosyntetica 34, 321-342.

Maksymiec, W. (2007). Signaling responses in plants to heavy metal stress. Acta Physiol. Plant 29, 177187.

Marin, E., Jouannet, V., Herz, A., Lokerse, A. S., Weijers, D., Vaucheret, H., Nussaume, L., Crespi, M., and Maize, A. (2010). miR390, Arabidopsis TAS3 tasiRNAs, and their AUXIN RESPONSE FACTOR targets define an autoregulatory network quantitatively regulating lateral root growth. Plant Cell 22, 1104-1117.

Navarro, L., Dunoyer, P., Jay, F., Arnold, B., Dharmasiri, N., Estelle, M., Voinnet, O., and Jones, J. D. (2006). A plant miRNA contributes to antibacterial resistance by repressing auxin signaling. Science 312, 436-439.
Panou-Filotheou, H., Bosabalidis, A. M., and Karataglis, S. (2001). Effects of copper toxicity on leaves of oregano (Origanum vulgare subsp. hirtum). Ann. Bot. 88, 207-214.

Peláez, P., Trejo, S. T., Iñiguez, L. P., Estrada-Navarrete, G., Covarrubias, A. A., Reyes, J. L., and Sánchez, F. (2012). Identification and characterization of microRNAs in Phaseolus vulgaris by high-throughput sequencing. BMC Genomics 13, 83. doi: 10.1186/1471-2164-13-83

Phillips, J., Dalmay, T., and Bartels, D. (2007). The role of small RNAs in abiotic stress. FEBS Lett. 581, 3592-3597.

Qi, X., Zhang, Y., and Chai, T. (2007). Characterization of a novel plant promoter specifically induced by heavy metal and identification of the promoter regions conferring heavy metal responsiveness. Plant Physiol. 143, 50-59.

Quinn, J. M., Barraco, P., Eriksson, M., and Merchant, S. (2000). Coordinate copper and oxygenresponsive Cyc6 and Cpx1 expression in Chlamydomonas is mediated by the same element. J. Biol. Chem. 275, 6080-6089.

Rellán-Álvarez, R., Ortega-Villasante, C., Álvarez-Fernández, A., Campo, F. F., and Hernández, L. E. (2006). Stress responses of Zea mays to cadmium and mercury. Plant Soil 279, 41-50.

Reyes, J. L., and Chua, N. H. (2007). ABA induction of miR159 controls transcript levels of two MYB factors during Arabidopsis seed germination. Plant J. 49, 592-606.

Romero-Puertas, M. C., Corpas, F. J., Rodriguez-Serrano, M., Gomez, M., del Rio, L. A., and Sandalio, L. M. (2007). Differential expression and regulation of antioxidative enzymes by cadmium in pea plants. J. Plant Physiol. 164, 1346-1357.

Schommer, C., Palatnik, J. F., Aggarwal, P., Chételat, A., Cubas, P., Farmer, E. E., Nath, U., and Weigel, D. (2008). Control of jasmonate biosynthesis and senescence by miR319 targets. PLoS Biol. 6, e230. doi: 10.1371/journal.pbio.0060230

Schützendübel, A., and Polle, A. (2002). Plant responses to abiotic stress: heavy metal induced oxidative stress and protection by mycorrhization. $J$. Exp. Bot. 53, 1351-1365.

Schützendübel, A., Schwanz, P., Teichmann, T., Gross, K., LangenfeldHeyser, R., Godbold, D. L., and
Polle, A. (2001). Cadmium-induced changes in antioxidative systems, hydrogen peroxide content, and differentiation in Scots pine roots. Plant Physiol. 127, 887-898.

Sharma, S. S., and Dietz, K. J. (2009). The relationship between metal toxicity and cellular redox imbalance. Trends Plant Sci. 14, 43-50.

Si-Ammour, A., Windels, D., ArnBouldoires, E., Kutter, C., Ailhas, J., Meins, F., and Vazquez, F. (2011). MiR393 and secondary siRNAs regulate expression of the TIR1/AFB2 auxin receptor clade and auxinrelated development of Arabidopsis leaves. Plant Physiol. 157, 683-691.

Sunkar, R., Kapoor, A., and Zhu, J. K. (2006). Posttranscriptional induction of two $\mathrm{Cu} / \mathrm{Zn}$ superoxide dismutase genes in Arabidopsis is mediated by downregulation of miR398 and important for oxidative stress tolerance. Plant Cell 18, 2051-2065.

Sunkar, R., and Zhu, J. (2004). Novel and stress-regulated microRNAs and other small RNAs from Arabidopsis. Plant Cell 16, 2001-2019.

Thornton, F. C., Schaedle, M., and Raynal, D. L. (1986). Effect of aluminum on the growth of sugar maple in solution culture. Can. J. For. Res. 16, 892-896.

Torres, M. A., Jones, J. D. G., and Dangl, J. L. (2006). Reactive oxygen species signaling in response to pathogens. Plant Physiol. 141, 373-378.

Valdés-López, O., Yang, S. S., AparicioFabre, R., Graham, P. H., Reyes, J. L., Vance, C. P., and Hernández, G. (2010). MicroRNA expression profile in common bean (Phaseolus vulgaris) under nutrient deficiency stresses and manganese toxicity. New Phytol. 187, 805-818.

Vidal, E. A., Araus, V., Lu, C., Parry, G., Green, P. J., Coruzzi, G. M., and Gutiérrez, R. A. (2010). Nitrateresponsive miR393/AFB3 regulatory module controls root system architecture in Arabidopsis thaliana. Proc. Natl. Acad. Sci. U.S.A. 107, 44774782.

Wei, W., Zhang, Y., Han, L., Guan, Z., and Chai, S. T. (2008). A novel WRKY transcriptional factor from Thlaspi caerulescens negatively regulates the osmotic stress tolerance of transgenic tobacco. Plant Cell Rep. 27, 795-803.

Wojtaszek, P. (1997). Oxidative burst: an early plant response to pathogen infection. Biochem. J. 322, 681-692.
Xie, F. L., Huang, S. Q., Guo, K., Xiang, A. L., Zhu, Y. Y., Nie, L., and Yang, Z. M. (2007). Computational identification of novel microRNAs and targets in Brassica napus. FEBS Lett. 581, 1464-1474.

Yang, Z. B., You, J. F., Xu, M. Y., and Yang, Z. M. (2009). Interaction between aluminum toxicity and manganese toxicity in soybean (Glycine max). Plant Soil 319, 277-289.

Yamasaki, H., Abdel-Ghany, S. E., Cohu, C. M., Kobayashi, Y., Shikanai, T., and Pilon, M. (2007). Regulation of copper homeostasis by microRNA in Arabidopsis. J. Biol. Chem. 282, 16369-16378.

Yamasaki, H., Hayashi, M., Fukazawa, M., Kobayashi, Y., and Shikanai, T. (2009). SQUAMOSA promoter binding protein-like 7 is a central regulator for copper homeostasis in Arabidopsis. Plant Cell 21, 347-361.

Zhou, Z. S., Huang, S. J., and Yang, Z. M. (2008). Bioinformatic identification and expression analysis of new microRNAs from Medicago truncatula. Biochem. Biophys. Res. Commun. 374, 538-542.

Zhou, Z. S., Zeng, H. Q., Liu, Z. P., and Yang, Z. M. (2012). Genome-wide identification of Medicago truncatula microRNAs and their targets reveals their different regulation by heavy metal. Plant Cell Environ. 35, 86-99.

Conflict of Interest Statement: The authors declare that the research was conducted in the absence of any commercial or financial relationships that could be construed as a potential conflict of interest.

Received: 29 February 2012; accepted: 04 May 2012; published online: 21 May 2012.

Citation: Mendoza-Soto AB, Sánchez F and Hernández G (2012) MicroRNAs as regulators in plant metal toxicity response. Front. Plant Sci. 3:105. doi: 10.3389/fpls.2012.00105

This article was submitted to Frontiers in Plant Genetics and Genomics, a specialty of Frontiers in Plant Science.

Copyright (c) 2012 Mendoza-Soto, Sánchez and Hernández. This is an open-access article distributed under the terms of the Creative Commons Attribution Non Commercial License, which permits non-commercial use, distribution, and reproduction in other forums, provided the original authors and source are credited. 